\title{
Farklı Dönemlerde Mimaride Kullanılan Cam Binalar ve Yapısal Özellikleri
}

\section{Glass Buildings Used in Architecture in Different Periods and Their Structural Properties}

\section{Özlem SAĞLIYAN SÖNMEZ ${ }^{a, *} \bigcirc$ SUna ÇETİN $b @$}

\begin{abstract}
a Nevşehir Hacı Bektaş Veli Üniversitesi, Avanos MYO, El Sanatları Bölümü, Nevşehir, 50500, Türkiye b Çukurova Üniversitesi, Güzel Sanatlar Fakültesi, Seramik Bölümü, Adana, 01380, Türkiye
\end{abstract}

\author{
Article history: Received 19-06-2019 / Accepted 23-06-2020
}

\section{ÖZET ABSTRACT}

19. $y y^{\prime} d a n$ günümüze kadar geçen zaman içerisinde, geniş olanak yelpazesine sahip mimari yapılar, cam duvarların da kullanılmasılla hafif, şeffaf ve havadar görüntülü yapıların gelişmesine olanak sunmuştur. Her geçen gün mimarinin ve teknolojinin sınırlarının zorlandığı yüksek yapı tasarımında, şeffaflık, estetik görünümler son yıllarda tasarımcılar ve mühendisler için tercih edilen bir malzeme olarak camı karşımıza çıkarmaktadır. Cam üzerinde yapılan teknolojik çalışmalar ve bunun sonucundaki olumlu gelişmeler mimarlar için camı daha çekici bir malzeme yapmıştır. Özellikle çelik ve camın mimari yapılarda birleşmesi saydamlık ve hafiflik yolunu açarak bu alanda yeni gelişmeler sağlamıştır. Görünen o ki camın gelişmeye açık bir malzeme olduğu gün geçtikçe daha çok kabul edilmekte ve cam mimari, artık strüktüre olarak da yer almaktadır. Bir zamanlar bir ütopyadan ibaret olan cam mimarisi, günümüzde artık bir gerçek haline gelmiştir. Bu çalışma, camın mimari yapılarda farklı dönemlerdeki gelişimi uygulanmış örneklerle birlikte anlatılmakta ve günümüzde yapı malzemesi olarak mimari alanda geldiği konumu açıklanmakta; ayrıca farklı dönemlerde mimaride kullanılan cam binaların yapısal özellikleri ve bu binalarda kullanılan cam çeşitlerinin özellikleri de verilmektedir. Çalışma 9 adet mimari yapı hakkında yapılan nitel araştırmaların birleştirilmesi sonucu oluşturulmuştur. Bu anlamda bu çalışma içerisinde 9 adet mimari yapı ele alınmış ve bunlar yapısal olarak incelenerek cam binalara örnek olarak sunulmuştur.

Anahtar Kelimeler: Mimari Mimari Cam Mimari Tasarım Cam Binalar
From the 19th century to the present, architectural structures with a wide range of possibilities have enabled the development of light, transparent and airy structures with the use of glass walls. In the high-rise building design, where the boundaries of architecture and technology are challenging every day, transparency and aesthetic appearances offer glass as a preferred material for designers and engineers in recent years. Technological studies on glass and the resulting positive developments have made glass a more attractive material for architects. In particular, the combination of steel and glass in architectural structures has opened the way for transparency and lightness and has made new developments in this field. It seems that glass is a material that is open to development and is increasingly accepted and its use in architecture is increasing. Glass architecture, once a utopia, has now become a reality. This study explains the development of glass in architectural buildings with examples that have been applied in different periods, and explains the position of the glass as a building material in the field of architecture today; also, the structural properties of glass buildings used in architecture in different periods and the properties of glass types used in these buildings are given. The study was created by combining qualitative research on 9 architectural structures. In this sense, 9 architectural buildings have been discussed in this study, and structurally examined and presented as examples to glass buildings.

Keywords: Architectural Architectural Glass Architectural Design Glass Buildings 


\section{MÍMARİDE CAM}

Mimarlığın, betonarme, çelik, metal, cam, plastik malzemelerin kılıktan kılığa sokulup taşıyıcı ve sınırlayıcı fonksiyonlara dönüştürüldüğü modern strüktür anlayışı çerçevesinde: "fonksiyonalizm, rasyonalizm, brütalizm, kübizm, dadaizm, neoplastizm, süpremarizm, fütürizm, sürrealizm, ekspresyonizm, konstrüktivizm, dekonstrüktivizm, postmodernizm..." ile tariflenen ve devamlı yenilenen, bir öncekini inkâr eden arayışlar oluşmuştur. Özellikle teknolojinin de gelişmesi strüktürün ön plana çıkmasına ve binaların yükselmesine, yeni malzemelerin doğuşu (plastik ve kimyasallar) yeni biçimlerin üretimine, bilgisayarın ortaya çıkışı akla gelmeyecek tasarımlara imkân vermeye başlamıştır.

Mühendislik teknolojisindeki gelişme mimarların ufkunu açarken, mimarlar da malzeme teknolojisinin gelişimini tetiklemişlerdir. Cam teknolojisi çağdaş mimari tasarım taleplerine paralel olarak gelişmiş, mimarlara şeffaf yapılar gerçekleştirme imkânı sağlamıştır. Bu yapı tarzı cam yüzeyli cephelerin yapılabilirliğini sağlayan mühendislik teknikleriyle birleştirilerek günümüze kadar gelmiştir. Camın cephe kaplaması olarak kullanılması, sonsuzluk ve boşluk hissinin daha ileriye götürülebilmesi düşüncesinin gelişmesini sağlamıştır. Giydirme cam cepheli binalar için yapılan ilk örnekler yapı strüktüründe önce beton karkasların giydirme cam kaplanması, daha sonra çelik-cam kaplama örnekleriyle başlamış, ayrıca eşzamanlı olarak cam teknolojisinde de mimarın ihtiyacına paralel ısı kontrollü, "mor ötesi" ışınlara karşı korumalı, kir tutmayan ve "ısı kontrollü güneş geçirgen çözümler" üretilmesini sağlamıştır (Olcay, 2009).

Modern Mimari ile cam, fonksiyonel olmasının dışında, estetik ve sembolik olarak da kullanılmaya başlanmış ve dış mekân ve iç mekân arasındaki sınırların belirsizleştiği, iç-dış geçişliliğinin sağlandığı, yapı kabuğunun etkisinin nötrleştirildiği bir anlayış geliştirilmiştir (Ayçam, 2002).

Dilekçi'ye (2000) göre: "Teknolojinin cama verdiği bin bir türlü özellik onun fiziksel boyutunun da değişimine yol açmıştır. Cam artık saydam olmayı değil yarı saydam olma, reflekte olma, enerji üretme ve koruma gibi özellikleri de içeren çok anlamlı bir malzeme haline gelmiştir. Ayrıca saydamlığı artık sadece cam da vermemektedir."

Hayata geçirilen ofis projesi; ikonik mimarisi, çevresel tasarımlar, akıllı kontrol sistemleri ve evrimsel nitelikteki mühendisliğin bir araya gelmesiyle oluşturuldu. James Law göre: "21. yüzyılda, binalar 20. yüzyıldan farklı olacaktır." Artık somut, çelik ve camdan değil, aynı zamanda teknoloji, multimedya, istihbarat ve etkileşimin yeni maddi olmayan malzemeleri hakkında da değiller. Bunu sadece tanımak, ışığa, yeni bir mimari şekli getirecektir.

XXI. yüzyılın başlarından itibaren yapısal cam üzerinde devam eden çalışmalar gelecekte, esneklik ve strüktürel dayanıklılık sağlayacak "plasto-cam" ve "karbo-cam" da daha ileri gelişmeler olacağını göstermiştir. Değişken iletimli camlar, binaların içeriden ve dışarıdan görünüşleri üzerinde hareketli bir etkiye sahip olacak ve pencerelerin, yarı saydam duvarların ve perdelerin yerini alacaktır. Likit kristal görüntü teknolojisi, dekorasyon, bilgi teknolojisi ve iletişim işlevi ile birleştirilebilecek; iç cam duvarlar ve dış kabuk, içinde bilgiler olan elektronik görüntüler ya da içinde renk olan temel şablonlar şekline dönecektir. Böylelikle binanın bütün karakterinin anında değişmesinin olanaklı hale gelmesi mümkün olabilecektir (Utkutuğ, 2002).

\section{2. ÖNEMLİ CAM BİNALAR}

\subsection{Hearst Kulesi}

Hearst Tower, mimarı Norman Foster tarafından 2006 yılında tamamlanmış ve binanın yapımı ise üç yıl sürmüştür. Şaşırtıcı gökdelen 42 katlı ve Manhattan'ın manzaralarına bakmaktadır. Gökdelenin alt kısmı ise oldukça ilginçtir;1928 yılında inşa edilmiş tarihi bir binanın içerisine Norman Foster bu şaşırtıcı kuleyi yerleştirilmiştir. Hearst Tower, tarihi binanın lobisinden 20 metre yüksekliğindeki bir tavan ile yükselmektedir.

New York'un ilk Altın LEED sertifikalı binası olan "Hearst Kulesi"nin en dikkat çekici özelliği ise elmas biçimindeki, eğimli forma sahip olan dış cephesidir. Diagrid adı verilen taşıyıcı sistemlerin üzerine oturtulmuş üçgen dış cephe kaplamaları, 10. kattan itibaren içeri doğru 
$75^{\circ}$ eğimle dört kat kadar yani 16 metre yükselmektedir. Daha sonra dışarı doğru $105^{\circ}$ eğimle yükselip aynı biçimlenmeyi çatıya taşımaktadır. Ofis ve meydan kısımlarının doğal ışıkla aydınlatılmasını sağlayan giydirme cephe, 65 adet, 4 kat yüksekliğinde çelik üçgen elemanlardan oluşmaktadır. Cephe elemanlarında, askılarda ve iç kısımdaki kolonlarda kullanılan çeliklerin \%90'ı geri dönüştürülebilen malzemelerden yapılmıştır. Giydirme cephe, bina içine doğal ışık alırken, ısınmaya neden olan güneş ışınımını azaltacak özellikte Low-E cam kullanılarak yapılmıştır (Zinzade, 2010).

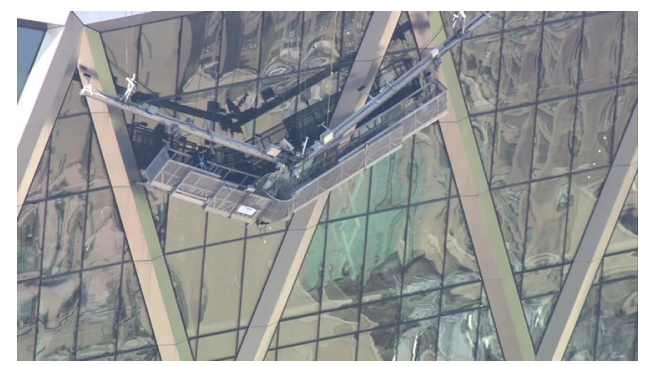

Şekil 1. Hearst Kulesi (URL-15, 2019)

Hearst Kulesi, orijinalinde 6 katlı kireç taşı cepheli betonarme bir bina olarak tasarlanmıştır. Foster\&Partners ile Gensler, binanın orijinal retro kolonlarını, korkuluklarını, heykellerini ve pencerelerini korumuş, restore etmiştir. Yapılanlar sonucu standart bir ofis binasına oranla \%26 daha az enerji tüketimi sağlanmaktadır. Kireç taşı atrium zemininde gömülü polietilen tüpler, su sirkülasyonuyla yazın soğutmayı kışın da ısıtmayı sağlamaktadır (Altum, 2009).

Doğal ışı̆̆ın miktarına göre suni aydınlatmaları kontrol eden sensörler bulunmaktadır. Bina boşken ışıkların ve bilgisayarların kapatılmasını sağlayan hareket sensörleri bulunmaktadır. Yüksek enerji etkinliği sağlayan ısıtma ve havalandırma sistemleri yılın \%75'inde dış havayı ısıtmada ve havalandırmada kullanmaktadır. Ofislerin havalandırmasında kullanılan ve gerektiğinde pompalama sistemiyle bina içindeki ve dışındaki bitkilerle ağaçların sulanmasında kullanılmak üzere, bina çatısında yağmur suyu toplama tankı bulunmaktadır. 10 katlı atriumda bulunan 2 kat yüksekliğindeki yağmur suyu şelalesi, sıcak sezonlarda atriumun soğutulmasını, kış aylarında da havanın nemlendirilmesini sağlamaktadır (Altun, 2009).

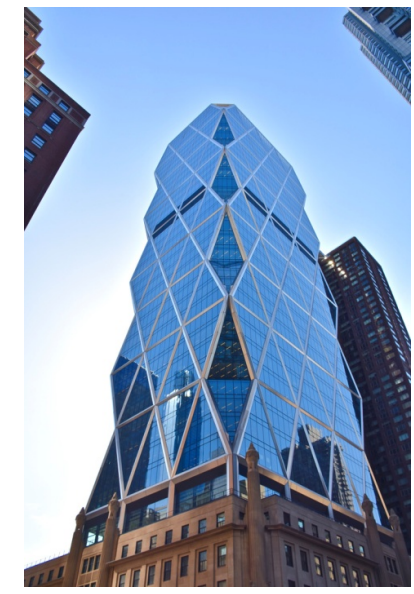

Şekil 2. Hearst Kulesi (URL-15, 2019)

\subsection{Dans Eden Ev}

Mimarlar, yüzyıl başında Prag'ın karakteristiklerinden birinin köşe kuleleri olduğunda anlaşmışlar ve bunun köşe başında yer alacak bina için bir çıkış noktası olmasını kararlaştırmışlardır. Daha sonrasında, çok sert etki yapacağı düşünülen bu kulenin yanına hafifletici bir etki yaratmak amacıyla şeffaf bir kütle eklenmesi düşünülmüş ve dans eden bir çifti çağrıştıran biçimiyle, birbiriyle kucaklaşan iki kule köşeyi vurgulamak üzere 
yerleştirilmiştir. Yukarıya doğru genişleyen bir silindir ve hemen yanında beli sıkılmış bir cam kule, ilginç bir şekilde şehrin mimari bağlamına ustaca uydurulmuştur (Hasol, 1998).

İkinci Dünya Savaşında yıkılan bir binanın yerine yapılan "dancing house" ilgili ilk çalışmaları mimar Milunic tarafından yapılmıştır. Hollanda kökenli bir sigorta şirketi olan NationaleNederlanden, Çek Cumhuriyeti'nin başkenti Prag'ın şehir merkezinde inşa ettirdiği binaya "dancing house" takma ismini vermiştir. Karşıtlık yöntemiyle tasarlanmış yapıda yükseklik dışında kütle ve çevre etkileri anlamında zıt kararlar alınmıştır. Yapı, dikkat çekici cam kütlesi ile çağdaşlığını net bir şekilde ortaya koymuştur (Duralı, 2007).

Köşe parselde yer alan yapıda, zeminde dükkanlar ve kahvelerin yer aldığı bir büro binası inşa edilmiştir. Binanın köşesindeki biri cam diğeri beton kuleler, dans eden bir çifti anımsattıkları için Literatürde daha çok, Amerikalı ünlü dansçı film yıldızları Ginger Rogers ve Fred Astaire'den esinlenilerek "Ginger ve Fred" olarak anılmaya başlanmışlardır. Fred Astaire ve Ginger Rogers'ın adlarıyla anılan bina, Prag'ın mimari, ekonomik ve siyasal yenileşmesinin bir simgesi olarak görülmektedir (Hasol, 1998).

Tasarımda şeffaflık ve masiflik dengeli bir birliktelik oluşturmuştur. Hemen bitişiğindeki doku ile pencere oranları benzeşse de, bunların organizasyonundaki hareketler ve oluşan akışkanlık ile tatı bir karmaşıklık oluşturmaktadır. Dans eden bina olarak anımasını sağlayan metaforik yaklaşımı ile önemli bir simge yapı haline gelmiştir (Düzgün, 2010).

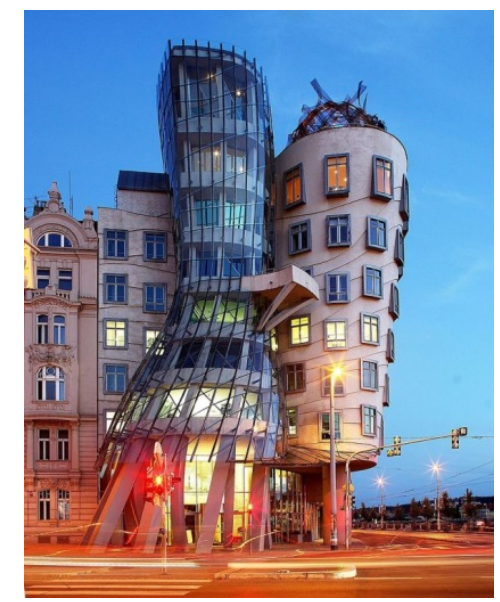

Şekil 3. Dans Eden Ev (URL-14, 2019)

\subsection{Aldar HQ}

Aldar HQ, dünyanın ilk küresel ofis binasıdır. Aldar Genel Merkezi, Orta Doğu'daki ilk yuvarlak yapıdır. "Büyük Deniz Kabuğu" olarak bilinen Abu Dabi'deki en büyük emlak şirketinin ve bölgede faaliyet gösteren çok önemli çokuluslu şirketlerin genel merkezlerine ev sahipliği yapmaktadır. MZ \& Partners Architects tarafından tasarlanan Aldar Genel Merkezi, Valencia'daki Exchange Building Konferansında En İyi Fütüristik Tasarım ödülünü kazanmıştır. ALDAR Properties'in yeni $\mathrm{HQ}$ binası belki de bugün dünyanın en eşsiz tasarımlarından biridir.

Mimar Marwan Zgheib Aldar Merkez Binası'nın tasarımcısı, bu yörenin geçmişteki geçim kaynağını oluşturan incilerin çıkarıldığı istiridye kabuğundan ilham alarak, bu simgesel değeri taşıyan ALDAR gökdelenini tasarlamıştır. ALDAR gökdelenin tam merkezinde, betonarme perdelerden oluşan iki adet çekirdek bulunurken, dış cephesinin çift yönde eğriliğe sahip olması ve dış cephesinin daire şeklinde olması hedeflenmiştir (Okbaz ve Savaşır, 2013). 


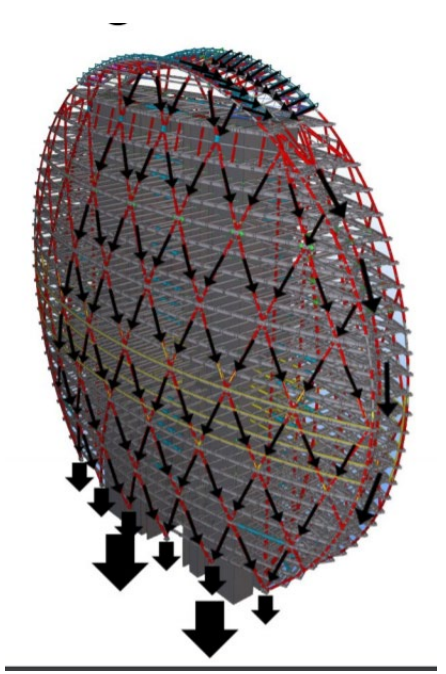

Şekil 4. Aldar HQ (URL-2, 2019)

Aldar Gökdeleni'nin milimetrik hassasiyette beton dökümü yapılamaması ve gökdelenin karmaşık geometrisi gibi nedenlerden dolayı binanın cephesinde çelik malzeme kullanılmak zorunda kalınmıştır. Mimar ALDAR, gökdeleninin tasarımını gerçekleştirirken, binanın panoramik İran Körfezi manzarasını kesmemesi için büroların genişliği ve pencerelerin yüksekliğini de göz önünde bulundurarak, çelik malzemeli bir dış iskelet yani "diagrid" kullanmaya karar vermiştir. Bu güçlü fakat ince çelik çerçeve gökdelene kendine has şeklini vermiş, böylece üzerine binen yükü güçlü kirişlerinden ve bağlantı noktalarından geçirip çekirdeklere aktarmıştır (URL-2, 2019).

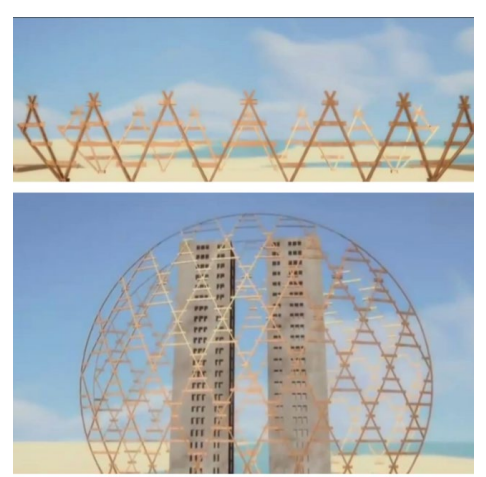

Şekil 5. Aldar HQ (URL-2, 2019)

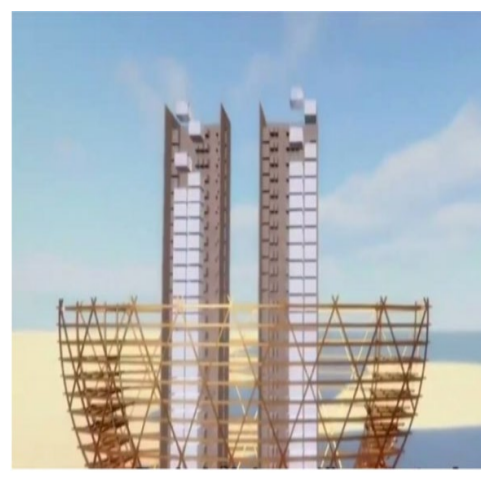

Şekil 6. Aldar HQ (URL-2, 2019)

Aladar Gökdeleni Airodek Panel ve Prop sistemi hafif alüminyum çerçeveli kontrplak panellerden ve ayarlanabilir dikmelerden oluşur. Her pervane daha sonra, alt kısmı oluşturmak için alüminyum panellerin dördünün yerine güvenli bir şekilde kilitlenebilen tepesinde bir taça sahiptir.

Uluslararası A Sınıfı standartlara göre inşa edilmiş HQ, 20 kata yayılmış $51.000 \mathrm{~m} 2$ prim ofis alanı, bodrum katında otopark ve podyum düzeyinde yardımcı perakende alanları sunmaktadır. Yaklaşık 120 metre uzaklıktaki HQ, Abu Dabi'deki ilk yeşil binalardan biri ve Abu Dabi silueti üzerinde bir dönüm noktası haline gelmiştir. HQ'nun mükemmel konumu, şehrin, kanalın ve denizin muhteşem manzarasını sunar ve yüksek hızlı asansörler ve Abu Dabi'deki en yüksek park oranlarından biri olan istisnai hizmetlerin entegrasyonu ile benzersiz bir çalışma ortamı sağlamaktadır. Bina, Abu Dabi'yi Dubai ve komşu GCC ülkelerine bağlayan ana arter yolu ağının hemen dışında bulunan ve Abu Dabi Uluslararası Havalimanı'ndan on dakikalık bir mesafede olan yerel ve uluslararası pazarlara mükemmel bir şekilde hizmet vermektedir (URL-19, 2019). 
Bütün bina, $40^{\circ} C^{\prime} y i$ aşabilen yaz günleri sıcaklığına sahip Abu Dabi çöl iklimine maruz kalan büyük bir cam mercek gibi görünmektedir. Bu zorlu koşullar ve yüksek iç yükler, yüksek performans ve güvenilir klima sistemlerinin kullanılmasını gerekli kılmaktadır Aldar Genel Merkezi, tüm merkezi ve çevre alanların iklimlendirilmesi için çok büyük hidronik klima santralleri kullanmaktadır. Tüm makineler ilk yirmi ikinci kattaki iki ayrı alana yerleştirilmiştir. Her birim 80.000 metreküp hava alabilmekte, farklı alanların ihtiyacına göre taze ve geri dönen havayı filtrelemekte, soğutmakta ve nemini almaktadır. Değişken hava akımı tipi (VAV) dağıtım sistemi, inverter üzerinden bir denetim sistemi tarafından kontrol edilmektedir. Geri kalan ev içi alanlara tavana monte edilmiş 80'den fazla hidronik fan coil cihazı servis edilmektedir. Klima santrallerinde kullanılan paneller $50 \mathrm{~mm}$ ısı ve ses yalıtımı ile donatılmıştır. Bu, gürültü seviyesi ve enerji kayıplarının azalmasına izin vermektedir. Tüm sistem, daha fazla bireysel ihtiyaca adapte olmak için ilave soğutulmuş su, temiz hava ve egzoz sistemi sağlamaya hazır olarak yapılmıştır (URL-2, 2019).

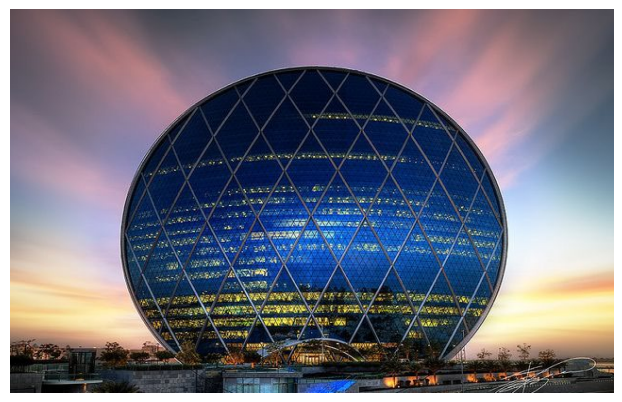

Şekil 7. Aldar HQ (URL-2, 2019)

\subsection{Cartier Çağdaş Sanatlar Merkezi}

Cartier binasında mimari etki masif kütlenin sınırlarını aşan, bulanıklaşan, yüzeyler arasında bir ilişkiyi anlatan bir yoruma sahiptir. Binanın başladığı ve bittiği noktalar belirginsizleşmiştir; çünkü yapay şeffaf bir cephe arkasından gökyüzü ve sedir ağaçlarının gözükmesiyle sınırların ve katmanlaşmanın vermiş olduğu algı karmaşası ile yeni bir cephe kavramı oluşturulmuştur (Düzgün, 2010).

Yapı kabuğu, öndeki katmanının, dokusu, oranları, oluşturduğu masif yüzey ile ilk başta tarihi çevresiyle zıt bir tutum sergiliyor gibi gözükse de, gece ve gündüzleri farklı ışık algısı ve arada ağaçların da bulunduğu değişik katmanları ile bina kütlesinin siluetinin harmanlamasıyla oluşan karmaşık fakat dengeli bir birlik oluşturmaktadır (Düzgün, 2010).

Nouvel'in tanımıyla iç ve dış arasındaki bariyerin kaldırılmasını hedefleyen daimi bir arayış, bir saydamlık çalışması olan yapıda cam kullanılmış ve şeffaf bir cephe etkisi yaratılmıştır. Karşıtlık yöntemiyle tasarlanan yapıda cephe etkisi olarak sade ve nötr bir etki de elde edildiğini söylemek yanlış olmaz (Duralı, 2007).

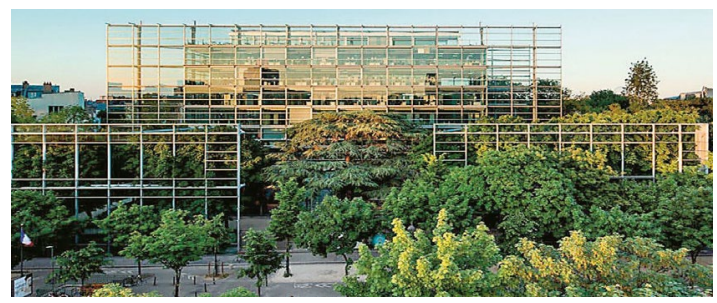

Şekil 8. Cartier Çağdaş Sanatlar Merkezi (URL-16, 2019)

\subsection{Kusthaus Sanat Merkezi}

Bina Avusturya'nın ikinci büyük şehri olan Graz kentinde Mur Nehri'nin kenarında yeni bir kent simgesi haline gelmiş olan Kunsthaus Graz, Londralı mimarlık ofisi CRAB Studio tarafından tasarlanmıştır.

Yapı, yarı saydam plastik esaslı mavi prefabrik panellerle kaplanmıştır. Uygulama aşamasında, yapının dış kabuğu üç boyutlu olarak modellenmiş ve parçalara bölünmüştür. 
Fabrika ortamında üretilen parçalar şantiyeye montajı yapılmak üzere getirilmişlerdir. Profesyonel formu şaşırtıcı bir etki yaratmaktadır, malzeme seçimi, kütle ve çevresel etkiler anlamında çevreyle hiçbir şekilde uyum içinde olmayan bina sadece yükseklik anlamında çevreye uymaktadır (Duralı, 2007).

Devasa bina mavi parıltılı, sırlı cephesi, yumuşak formları ile eski yapılarla organik bir bağ da kuruyor. Binanın pleksiglas kaplamasından çıkan hava kabarcıklarına benzeyen koniler, ideal ışıklandırma için kuzeye doğru eğimli olarak yerleştirilmiş. Konilerin görünümü binanın hem dış hem de iç cephesine kendine özgü bir yapı kazandırmış. Kunsthaus Graz'ın pleksiglas (akrilik-plastik cam) ile kurgulanmış dış kabuğu yapının en dikkat çekici noktalarından. Bu kabuk, üstünde dışarı doğru uzanan delikler bulunduran bir yapıya sahip. Böylece yapının içine doğal ışığın girmesini sağlanmış. Yapının asıl cephesini oluşturan güney cephesinin yanı sıra kuzey cephede ise farklı bir meyille kurgulanmış bu delikler ile bu cepheden kontrollü bir doğal ışık alınımı gerçekleştirmektedir (URL-2,2019).

Binanın cephesine gömülü olan yaklaşık 1.000 adet floresan halka, binaya görsel anlamda ekstra bir çekicilik kazandırıyor. Floresan halkalar için gerekli olan enerjinin büyük kısmı ise binanın parlak tavanındaki güneş panelleri tarafından sağlanıyor Bu kısım binan güney cephesini oluşturuyor. Bu cephede, her bir lambanın bireysel olarak ayarlanabilir parlaklığıyla -sonsuzdan 20 çerçeve/dakikaya kadar- film ve animasyon gösterimleri yapılabilen bir tür ekran oluşturuyor. Kabuğun asıl mimari konsepti cepheyi düşük çözünürlüğe sahip bir bilgisayar, bir tür 'iletişimsel ekran' yaratmaktır. Böylelikle CRAB Studio, alışılmadık kurgusuyla mimari, teknoloji ve bilgiyi birleştiren bir tasarım ortaya koyuyor. BIX Media adı verilen bu teknoloji ile merkezi bir bilgisayar tarafından büyük boyutlu ekrana aktarılan görüntüler sanat projeleri için önemli bir platform sunmaktadır (URL-8, 2019).

İki ana girişi bulunan müze, sunduğu iletişim ve eğlence olanakları ile de çok yönlü bir kamusal alan yaratıyor. Sergi alanı ayarlanabilir gün ışığı ve yapay ışık kaynakları ile donatılmıştır (URL-2,2019).

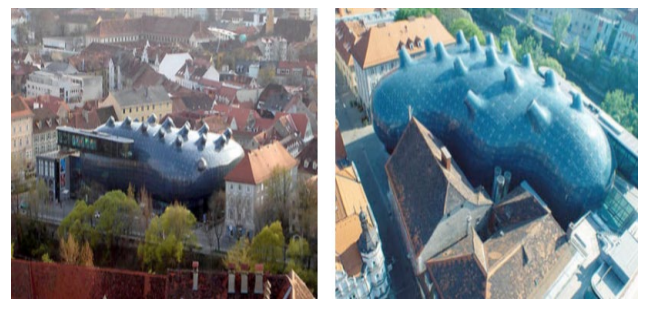

Şekil 9. Kusthaus Sanat Merkezi (URL-8, 2019)

\subsection{Pompidou Sanat Merkezi}

Fransız Cumhurbaşkanı Pompidou'nun görevde kaldığı dönemin güçlü bir imgeyle hatırlanması için modern sanatlar müzesi inşa etmeye karar vermesiyle, açılan uluslararası yarışmada seçilen bir proje olarak yapılmıştır. Uluslararası bir yarışma sonucunda seçilen bu proje, Renzo Piano ve Richard Rogers'in ortak yaptığı tasarımıdır. Pompidou'nun öncelikli hedefi çağdaş sanatı halka tanıtmak, mimarların buna verdiği tepki de geleneksel bir müze inşa etmemek" olmuştur. Yapı 1971-1977 yılları arasında inşa edilmiş ve 31 Ocak 1977'de açılmıştır. Yapı içinde konumlandığı hareket sistemine aykırı bir özellik göstermez, fakat önündeki meydan ile sisteme bir zenginlik katar.

Mimarlarının yorumlarına göre, projenin önemli noktalarından biri, gelecekteki olası düzenlemelere olanak verecek bir biçimde iç mekanı bu duruma engel teşkil edebilecek taşıyıcılar, tesisat boruları gibi elemanlardan arındırılmış olması, bu donatı elemanlarının dışarıya alınarak yapı kabuğunun metal çerçeveler, koridorlar ve çeşitli tesisat borularından oluşmuş olmasıdır. Ayrıca cam bir tüple çevrelenen kabuk, içindeyken tüm Paris'in görülebildiği yürüyen bir merdivenle insanların çekim noktasını olmaktadır (URL-23, 2019). 


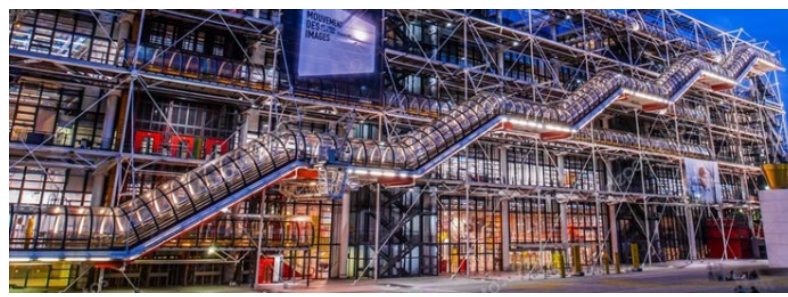

Şekil 10. Pompidou Sanat Merkezi (URL-17, 2019)

Yapının ebatları çevrenin hacimsel örüntüsü ile uyum içerisindedir. Yapı ve önündeki meydan çevredeki ortalama birer yapı adası büyüklüğünde ve geometrisindedirler. Diğer yapı adaları birçok yapıdan oluşurken Pompidou Kültür Merkezi tek bir yapıdır. Fakat yapının dışında bulunan kolonlarının verdiği güçlü düşey etki sebebiyle çevresindeki tek yapıların ölçeğine uyum gösterir. Yapı ve önündeki meydan, çevrenin hacim ve dolu-boş değerlerine uyarlar.

Yapının yüksekliği, çevresindeki yapılardan yüksektedir. Bu fark, çevredeki yollardan ve öndeki meydandan algılanmaz ve bir ölçek problemi yaratmaz, fakat yapıya kent ölçeğinden, örneğin Montmartre tepesinden bakıldığında yapı çevresinden ayırt edilmektedir (Cambaz, 2009).

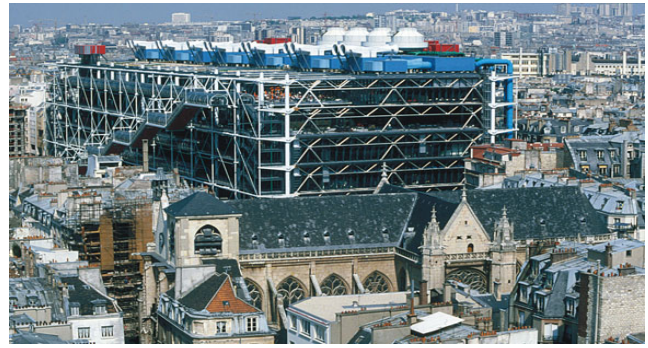

Şekil 11. Pompidou Sanat Merkezi (URL-17, 2019)

Paris'in genelinde yapılar betonarme karkas ve kâgir yığmadır. Cepheleri ise sıva ve üzerinde genellikle grinin hakim olduğu pastel renkli boya ile kaplıdır. Pompidou Kültür Merkezi'nin malzemesi ise buna kontrast olarak çelik ve camdır. Yapı her biri pastel değil, doymuş olan sarı, kırmızı, mavi gibi çevrede bulunmayan renklere sahiptir. Yapının diğer konularda gösterdiği çevrenin formülünü devam ettirme tavrı, malzeme ve renk konusunda yoktur. Bu konuda çevrenin tamamen zıttı olan bir yol seçilmiştir (Duralı, 2007).

Pompidou Kültür Merkezi, kendine ait teknolojik estetiğini, yapısal sistemlerin açığa vurulması yoluyla beyan eden, uzay çağının habercisi yeni bir bakış açısının, High Tech Mimarlığı olarak adlandırılan bir akımın öncülerindendir (Düzgün, 2010).

\subsection{The Shard Birleşik Krallık}

The Shard, 310 metre yüksekliğe sahip çok işlevli bir binadır. Ofisler, konut katları, otel (Shangri-La), restoranlar ve manzara galerileri (Londra manzarası), binanın içindeki ayrı katlarda yer almaktadır. 11 bin adet cam panelle döşeli olan dış cephesi, ilk kez bir peçetenin üzerine mimarı Renzo Piano tarafından 2000'de çizilmiştir. The Shard'ı tasarlarken, Londra kiliselerinin kulelerinden ve 18. yüzyılda yaşayan Venedikli ressam Canaletto'nun resimlerindeki uzun gemi direklerinden ilham alan İtalyan mimar Renzo Piano, 95 katlı iş, alışveriş ve yaşam merkezini Thames Nehri'nden çıkan sivri bir heykel olarak düşlemiş. 95 katlı binanın yapımına 2009'da başlanmış ve 2012'de tamamlanmıştır. Binanın büyük bir kısmı Katar'a aittir. Renzo Piano'nun en son projesidir (Tohumcu ve Çakmaklı, 2017).

Yapıldığı tarihte İngiltere ve Avrupa Birliği'nin en yüksek binası, Avrupa'nın en yüksek beşinci binası ve dünyanın en yüksek 96. binası oldu. Bina, Londra'nın merkezinde (Londra Köprüsü) yer almaktadır. Mimari olarak, tasarımda dikkat edilmesi gereken hususlar ön planda tutulmuştur; Shard çevresel ve sürdürülebilir kriterlere uygun tasarlanmıştır. Özellikle bu yüksek binanın sıra dışı mimari tasarımı dikkate alındığında, Shard'ın tasarım gereklilikleri hem mimari hem de inşaat aşamalarında ileri teknolojik yöntemlerle sağlanmıştır (Tohumcu ve Çakmaklı, 2017). 
The Shard'ın ince piramidal formu nedeniyle katlar, binanın farklı kullanım şekillerine göre alan ihtiyacını öngörerek planlanmıştır. 4. kat ile 28. katlar arası daha geniş açıklıklara ihtiyaç duyan ve değişik büyüklükte bölünmeye uygun ofis alanları olarak tasarlanmıştır. Ofislerin üstünde kalan 3 katta restoranlar ve barlar bulunuyor. Restoran ve barların üstünde yer alan Shangri-La Oteli binanın orta bölümünde yer almaktadır. Binanın üst bölümü ise rezidans yerleşim alanı olarak tasarlanmıştır. Evler, The Shard'ın ince yapısı sebebiyle şehri farklı açılardan görebilmektedir. Evlerin üstünde kalan son katlar yer seviyesinden 240 metre yükseklikten başlayan ve halka açık manzara seyir galerileri olarak düzenlenmiştir. Binanın çelik ve camdan yapılan zirvesi, her cephenin bitişi tepede birleşmeyecek şekilde tasarlandığından kule adeta Londra gökyüzünde kaybolmaktadır.

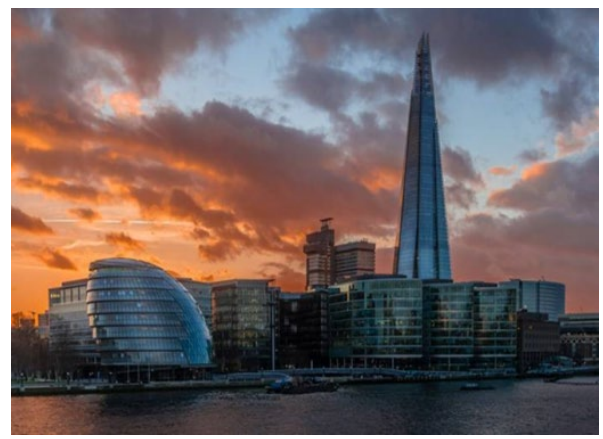

Şekil 12. The Shard Birleşik Krallık (URL-17, 2019)

The Shard'ın cephesindeki camlar sekiz farklı açıda ve kış bahçelerini havalandırmak amacıyla boşluklar bırakılarak yerleştirilmiştir. Bu sayede ışığı farklı açılarda kıran ve farklı görüntüler yansıtan camlarla kuleye hafiflik ve şeffaflık kazandırılmak istenmiştir. Cam kullanımı ve geometrik formu sayesinde hantal değil zarif bir kule inşa edilebilmiştir. Yansıtıcılığı artırmak amacıyla cephelerde özel bir sırlama tekniği ile elde edilen ekstra beyaz cam kullanılmıştır. Kullanılan 11 bin panel cam toplamda 56 bin metrekarelik bir alan kaplamaktadır (Parker, 2012).

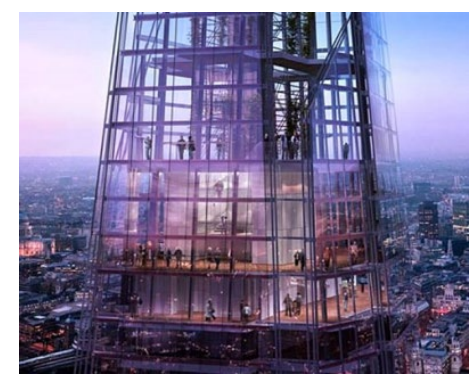

Şekil 13. The Shard Birleşik Krallık (URL-17, 2019)

İç ortamdaki ısı ve sıcaklığı ayarlamak için mümkün olduğunca dış ortamın ışık ve ısısından yararlanan otomatik sistemler kullanılmaktadır. Binanın ısıtma ve elektrik ihtiyacı bünyesindeki doğalgazla çalışan tesis tarafından sağlanmaktadır. Doğalgaz çok verimi bir şekilde elektriğe dönüştürülmekte, bu süreçte ortaya çıkan ısı da binaya sıcak su sağlamakta kullanılmaktadır (Masera, 2012).

Binanın mimarı Renzo Piano, "Binalar 18: 00'da kapandığında herkes binayı terk eder ve şehir içinde ölürse, 24 saat canlı bir bina olması gerekir" şeklinde tanımladığı sürdürülebilirlik hakkında ilginç bir yaklaşıma sahiptir. Bu bakış açısı, binayı fiziksel bir kentsel unsur olarak birleştirmenin, Piyano'nun (2013) Shard'ı "dikey şehir" olarak tanımladığı şehrin sosyal tarafı ile birleştirmeye başlaması olabilir. Bina son derece yüksek olsa da Piano, kapladığı alanın küçük olduğunu ve çeşitli kullanım alanlarına sahip olduğunu söylüyor. Sürdürülebilirlik kavramları hem sürdürülebilir hem de kentsel bir alan tanımlamak için fiziksel ve sosyal sorunları içermektedir. Renzo Piano ayrıca tasarımında enerji kullanımını da içeriyor: "Shard binası alttan üste daha küçük bir zemin alanı almaya başlarken (şekline bağlı olarak), enerji kullanımı azalıyor." Bu, "daha fazla enerji kullanan yüksek binalar" genel fikrini yıkmak için 
Piyano için en önemli noktalardan biridir. Piyano şöyle dedi: "Böyle bir bina tasarlamak bir orkestra ile oynuyor. Her klasik bina bir zamanlar moderndir ve şehirler harika yerlerdir, çünkü katmanlar halindedirler: Her bir katman eski katlar üzerine kuruludur. Bir şartta, yerin demiryollarından geldiği hiçbir şeyi yok etmedik. Bu bina hayat dolu olacak ve akşam 6'da kapanmayacak. Ayrıca insanlar binanın tadını çıkaracaklar çünkü herkesin erişebileceği bir kamu binası." Ayrıca, Piyano binanın sesini bölgenin nehre çok yakın olduğu bir sosyal ses olarak tanımlıyor. Londralılar için çok önemli. Piyano (2013), şehir olarak Londra'nın bu proje alanından başladığını ve bu projeyle Londra'nın enerjisini geri getirdiğine inandığını söylüyor. Piyano, Shard'ın cephesinin havanın, insanın ve şehrin aynası olduğunu söylüyor. Ayrıca, Londra'nın silüetinin asla aynı kalmayacağını ve Shard binasının ufuk çizgisini değiştirdiğini iddia ediyor. Shard binası gökyüzünün rengine bağlı olarak renk değiştirdiğinde, bu hareketlilik duygusunu yansıtmaktadır (Masera, 2012).

\subsection{Cybertecture Yumurtası}

Hindistan'ın Bombay kentinin tam merkezinde hayata geçirilen bu renkli proje, mimar James Law Cybertecture imzası taşıyor. James Law, Dünya Ekonomi Forumu Küresel Genç Liderler arasına seçilmiş ve aynı zamanda Siber mimarinin yeni tasarım öncüsüdür. Kendisi, tasarım konusunda inovasyon, teknoloji ve sürdürülebilirlik arzusuyla geleceğin dünyasını, insanlık için çok daha iyi tasarlama fikriyle 2001 yılında Cybertecture International'ı kurmuştur (URL1, 2019).

Mumbai'deki CYBERTECTURE EGG - tamamen sütunsuz ve güçlü yeşil özelliklere sahip, parametrik olarak tasarlanmış bir ofis binası; Abu Dabi'de bulunan TECHNOSPHERE binası Dünya gezegeninin ekolojisini sürdürülebilir bir mega yapı olarak taklit eden 10 milyon metrekarelik küresel bir akıllı ve yumurta şeklindeki binadır. Konsept tasarımcılara göre, dünyayı hayatın gelişmesine izin veren bir ekosistem olarak düşünerek ilham almışlardı. Bu akıllı dünya yumurtası, bir organizmanın kalbine yerleştirilmiş kendi kendine yeten bir tasarıma sahiptir. Cybertecture Yumurta gezegenimiz Dünya gibi bu binanın da sürdürülebilir bir eko sistemi mevcuttur. Zaten hayatın var olması, gelişimi ve evrimi için gerekli olan ekosistemi ile kendi kendine yeten bir gezegen olarak tasarlanmıştır. Böylece bina da yaşayan insanlara yaşayan bir dünya sunulmuş bu yaşayan dünya içerisinde de sanal alanlara erişim olanakları sunulmuş. Cybertecture Yumurta sının şeklide dünya gibi kürenin uzatılmış şeklinde ikonik bir binadır. Tasarım ve istihbarat sistemlerinin unsurları, binanın sakinlerine 'çalışmak için en iyi alanı' vermek için birlikte çalışacaktır. Bu da sağlıklarının izlenmesini içerir. Binada, tansiyon ve ağırlık da dahil olmak üzere halkın sağlığını takip etmek için tasarlanan tuvalette 'siber koruma sağlık' gibi bir dizi yenilikçi sistem bulunacaktır. Toplanan veriler gerekli görüldüğü takdirde alınabilir ve doktora gönderilebilir (URL-20, 2019).

Bina tasarım özellikleri arasında gökyüzü bahçeleri, PV güneş paneli çiftlikleri, akıllı cam cepheler ve su geri dönüşüm sistemi bulunmaktadır. 32.000 metrekarelik yumurta şeklindeki yapı, kentte etkileyici bir simge yapı oluşturmak için ikonik mimariyi, çevre tasarımını, akıllı sistemleri ve yeni mühendisliği bir araya getirerek 13 katlı ofis ve 400 park alanına ev sahipliği yapmaktadır (URL-1, 2019).

Dikdörtgen ofis binası, ısı kazancını azaltmak ve enerji yüklerini azaltmak için pasif güneş tasarımına sahiptir. Yükseltilmiş bir bahçe ayrıca, bina örtüsünün soğutulmasına yardımcı olmak için doğal bitki örtüsünü kullanarak sıcaklıkları kontrol edilir. Cybertecture Egg, de cepheye entegre edilmiş güneş fotovoltaik hücrelere sahiptir, böylece güneş enerjisi alternatif elektrik beslemesi sağlanmaktadır ve çatıda rüzgar türbinlerini kullanmaktadır. Bina gri su geri dönüşüm sistemi ile yönetilir. Bu şu demektir; içme suyu geri dönüşümünü, yağmur suyu geri kazanım sistemini, atık su arıtma sistemlerini, filtreleme ve sulak alan hücre sistemini bir arada içerir. Bu sistemler uygulandığında, bina yüzde 20 efektif geri dönüşüm oranı elde ediyor.

Binada bulunan gökyüzü bahçeleri binada yenilenmek için oksijenin sağlanması ve insanların dinlenmeleri için güneşe karşı yeşil alanlara sahiptir. Bu bahçeler binanın arkasını soğutmakta ve ıslak alan yatakları için su dönüşüm filtreleri görevi görmektedir. Binada Akıllı Cam Cephe uygulanmıştır. Binanın camlı güneş cephesi, çeşitli tonları ve camı harmanlayan 
son teknolojidir. Bina doğal yeraltı soğutma sistemi sağlayan yeraltı soğutma sistemi yerleştiren derin yeraltı rezervuarına sahiptir (URL-10, 2019).

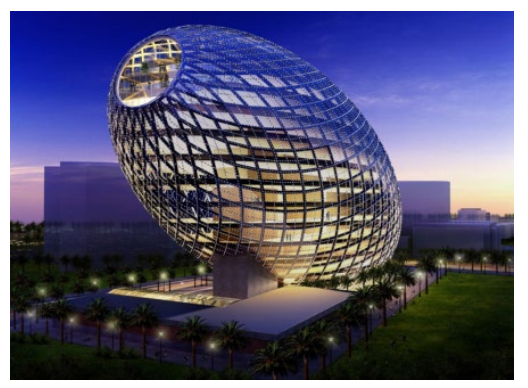

Şekil 14. Cybertecture Yumurtası (URL-1, 2019)

\subsection{St Mary Axe}

30 ST MARY AXE binası, 1992 yılında Baltık Borsasına İRA tarafından yapılan saldırının sonucu olarak çok fazla zarar gören Baltık Borsası binasının üzerine, üç yıldan daha kısa bir zamanda içerisinde 30 ST MARY AXE binasının inşası tamamlanmıştır. 2003 yılının aralık ayında bitirilen bina açılışı bazı aksaklılardan dolayı 2004'ün Mayıs ayında yapılmıştır (Futcher, 2013).

Gherkin olarak daha iyi bilinen 30 St Mary Axe, kat planı dilimlenmiş bir turşuya benzemekte ve Londra'nın sigorta bölgesinin kalbinde yer almaktadır. Site, Baltık Borsasını restore etmek ve 84 katlı bir Millennium Kulesi önerisi dahil olmak üzere, ne yapılması gerektiğiyle ilgili birçok tartışmalara girdi. 1997 yılında sigorta devleri Swiss Re, siteyi satın aldı ve binayı tasarlamak için Foster ve Partners şirketlerini bina yapımı için görevlendirdi (Kayhan, 2015).

Londra'nın ilk çevresel açıdan sürdürülebilir yüksek binası 180 metre yüksekliğinde ve 40 kattan oluşuyor. Bina, bu boyuttaki çoğu gökdelenin enerjisinin yaklaşık yarısını tüketmektedir. Sürdürülebilirlik kavramı, sürdürülebilirlik ilkelerinin çalışmalarına entegre edildiği binanın mimarı Norman Foster için temel bir temadır. Foster, mevcut enerji gereksinimlerinin bir kısmını çalıştıran sürdürülebilir binalar veya gelişen toplulukları destekleyebilen, şehirdeki herkesin yaşam kalitesini arttıran kentsel mahalleleri tasarlama yaklaşımına sahiptir. Bu yaklaşımın en önemli noktası ise kentsel yapıdaki yüksek bir binanın hem fiziksel hem de sosyal niteliklerini, sürdürülebilirliğin temel düşüncesi olarak ortaya koymaktır. Foster, ayrıca 30 St Mary Axe'nin şehri tanımlayan bina olduğunu söyler. 30 St Mary Axe, anıtsal tasarımı nedeniyle Londra için çok önemli bir yapıdır. Bina şehir silüetinde tanınabilir bir mimariye sahiptir ve Londra'daki ilk ekolojik yüksek binadır. Foster'a göre, 30 St Mary Axe, doğa ve işyerleri arasında iyi bir uyum yaratıyor çünkü binanın teknolojik ve mimari fikirleri geliştirmesi gerekiyordu." (Tohumcu ve Çakmaklı, 2017).

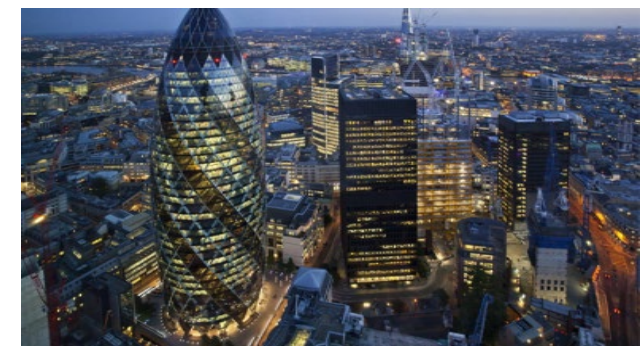

Şekil 15. 30 St Mary Axe (URL-4, 2019)

Giriş seviyesinde, 30 St Mary Axe, bina kullanıcılarını dışarıdakilerle birleştiren açık bir halk meydanı sunar. Bu ayırt edici form, sitenin kısıtlamalarına cevap verir: bina, eşdeğer büyüklükteki dikdörtgen bir bloktan daha ince görünür ve profilinin tabana doğru zayıflaması sokak seviyesindeki kamu alanını maksimize eder. Ayrıca, binanın her katındaki atriyumlar "sosyal odak" noktaları olarak tanımlanabilecekleri toplantı alanlarıdır. Bina, 16. katına ulaşana kadar her kat planında kademeli olarak genişler ve ardından doruk noktasına ulaşana kadar küçülür. Bu ayırt edici form, sitenin kısıtlamalarına cevap verir: Bina, eşdeğer 
büyüklükteki dikdörtgen bir bloktan daha ince görünür; yansımalar azalır ve şeffaflık artar; Binanın zemin katında incelmesi, kamusal alanı zemin seviyesinde arttırır. Profil, benzer boyuttaki bir doğrusal kule ile karşılaştırıldığında, yere yansıyan rüzgar miktarını azalttığından, cadde seviyesinde yaya konforunun korunmasına yardımcı olur.

30 St Mary Axe iki ana yapısal sistemden oluşmaktadır. Bunlardan ilki, yükün çoğunu alan çekirdek, diğeri ise çapraz köşeli bir yapı 'diagrid'. Olağandışı geometrinin ürettiği sorunları ele almak için, çevre çelik yapı çözümü bu bina için özel olarak geliştirilmiştir. Bu diagrid, 360 farklı düğümde birbirine bağlanan, farklı yönlerde spiral şeklindeki kesişen çelik boru bölümlerden oluşur. Bu düğümlerin her biri, farklı açılarda birbirine kaynaklanmış üç çelik levhadan oluşur. Her bir bağlantı 2 m yüksekliğe kadardır ve diagrid de 2500 ton çelik bağlarlar. Bu, geleneksel bir yapıya göre\% 20 daha az çelik gerektiren ve kütle sönümleyicisi gerektirmeyecek kadar sert olan son derece güçlü ve sert bir şasidir (URL-21, 2019).

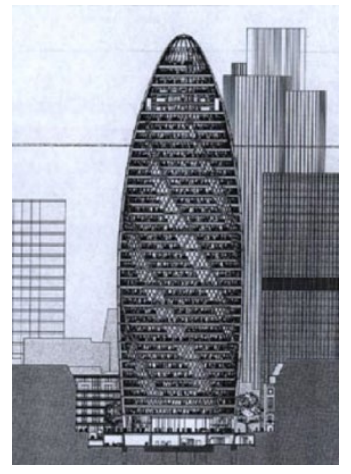

Şekil 16. 30 St Mary Axe (URL-4, 2019)

Döşeme çerçeveleme sistemi, $160 \mathrm{~mm}$ derinliğinde profil metal zemin kaplaması üzerine beton plakadır. Diagrid bu yükü alırken taban plakaları çapraz desteklerden arındırılmıştır. Tipik bir kat planında, üçgen şekilli boşluklar ışık hücreleri gibi hareket etmek üzere kesilmiş dairesel bir servis çekirdeğinin etrafında altı yapraklı bir plan vardır. Zeminler saat yönünde 5 derece döndürülerek her kat, altı sarmal ya da tirbuşon boşluğu yaratılır. Bu büküm atriyosu yangının yayılmasını önlemek için her altıncı katta kapatılmıştır (Munro, 2004).

Binanın yapısal gereksinimleri, Ribdeck 80'in sığ döşeme konstrüksiyonu ile birlikte daha uzun süreli çalışma kabiliyeti için seçilmesine izin vermiştir. Döşeme levhasının maksimum açıklığı 4,8 metredir ve tepesinde sadece hafif kumaş takviyesi ile iki saate kadar bir yangına dayanıklılık sağlamak için $160 \mathrm{~mm}$ derinliğinde hafif beton zemin döşemesi tasarlanmıştır (URL-21, 2019).

Ofis katları, dairesel bir servis ve asansör göbeği etrafında 1.5 metrelik bir ızgara üzerinde düzenlenmiş altı konuşmacı şeklinde düzenlenmiştir. Sonuç, tüm ofis parmaklarının 8,5 m'lik bir kuyu içi içerisindeki tüm kısımları maksimum 14 m 'kadeh cihaza' boyutudur. Hafif kuyular art arda gelen her katta 5 dereceye kadar dengelenir (URL-21, 2019).

Enerji tasarrufu sağlayan çift cidarlı cephe, alüminyum profilli ve çelik çerçeveli camdan yapılmıştır. Elmas şeklindeki camlara yerleştirilmiş 24.000 metrekarelik camdan oluşur. Ofis alanlarındaki zarf, çift camlı bir dış katmandan ve güneş kontrol panjurları içeren merkezi ve havalandırmalı bir boşluğu sandviçleyen tek camlı bir iç ekrandan oluşur. Bu boşluklar, tampon bölge görevi görerek mekanik ısıtma ve soğutma ihtiyacını azaltır ve ofislerden çekilen egzoz havası ile havalandırılır. Cephe elemanları; delikli alüminyum panjurlar, çekilmiş alüminyum cephe çerçevesi, açılabilir cam elek ve alüminyumdan bir sütun kılıfı. Klima sistemi, otomatik olarak açılan ışık kuyularındaki pencerelerden doğal havalandırma yardımı ile arttırılır. Bu sistem, binanın yılın\% 40'ına kadar enerji tasarrufu yapmasını sağlamaktadır (Anonim, 2008).

İki katlı yüksekliğe sahip zemin kat, halka açık avludan erişilebilen bir alışveriş merkezini oluşturmaktadır. Taşıyıcı cephe ile gömme cephe arasında oluşturulmuştur. Ofis kulesinin fuayesine ek olarak kiralık dükkanlar vardır. Eğik basmalı menteşeler girişi işaretler. Zemin katının üstünde 33 adet ofis katı bulunmaktadır. Binanın tepesinde - Londra'nın en yüksek 
işgal altındaki katı - üç katta da bir restoran, bir etkinlik odası ve başkentin 360 derecelik muhteşem panoramik manzarasını sunan bir kulüp odası bulunmaktadır (URL-22, 2019).

Foster'in basit, ayrıntılı bir silindir tasarladı. Bununla birlikte, hepsi bir arada, klasik, Barok, Minimalist ve Organik, rüzgar tünelinde aerodinamik olarak düzenlenmiş şık damla biçiminde hepsini birleştirdi. Bu nedenle, Foster'in "teknolojik, mimari, ekolojik, sosyal ve mekansal olarak radyal" olarak adlandırılması, kentin karmaşıklığını uyumlu hale getirmektedir (Firley ve Gimbal, 2011).

Norman Foster, rüzgarı yere yönlendirmek yerine, binanın ve cephesinin etrafındaki rüzgar akışını sağlamak için aerodinamik bir şekil tasarladı.

Kubbe, Londra'nın hafif mimarları Speirs ve Major konseptine göre geceleri bir deniz feneri gibi şehri gölgelemektedir. Kubbe, 30 m çapında bir çelik ve cam yapıdır ve çevre diagridinin tepesindeki desteğinden 22 metre yüksektedir. Kubbe çelik işi, kesişen fabrikasyon üçgen profillerin tamamen kaynaklı bir kafesidir. Bu yapısal düzenlemenin etkinliği, sadece $110 \mathrm{~mm}$ x 150 mm olan çok az çelik elemanlara neden olur. Binanın üst lensi tüm yapıdaki tek kavisli cam parçadır. 2.4 metre çapında ve 250 kg ağırlığındadır (Futcher, 2013).

\section{SONUÇ}

Çă̆ımızda yapı teknolojilerinin gelişimi her geçen gün hızla artmakta ve yapı malzemeleri de bununla birlikte çeşitlenmektedir. Malzeme ve teknolojinin sunduğu olanaklar tasarım sürecini etkilemekte ve bu sürece yön vermektedir. Bu süreç içerisinde mimaride cam da estetik olarak yapı tasarımlarında yer almakta ve kullanılmaktadır. Bu bakımdan günümüz mimarisinde varılan sonuç ne olursa olsun tasarımcı olarak farklılığını ortaya koyma ve özgün olma temel bir çaba halini almıştır. Son zamanlarda dünya da yaygın bir şekilde uygulanmaya başlayan camın cephelerde hafif olmaları, estetik görünümleri, imalat ve montajlarının kolay olması, dış iklime dayanıklılıkları nedeni ile kısa zamanda özellikle yüksek yapıların vazgeçilmez bir estetik malzemesini oluşturmaktadır. Cam işleme alanındaki yenilikler camı artık sadece pencerelerde kullanılan bir malzeme olmaktan çıkarmış; camı ısı ve ses yalıtımı sağlayan, güneşin aşırı parlaklığı ile radyasyon ısısını denetleyen ve yapı içini dış etkenlere karşı güvence altına alabilecek niteliklere sahip bir yapı kabuğuna dönüşmüştür. Mimarlık alanında yapıda malzeme kullanımı ve bu malzemenin yapıya uyumluluğu çok önemli bir görsel nitelik oluşturmaktadır. Makalede ele alınan yapılar bu tasarımlara birer örnek oluşturmakta ve cam gibi şeffaf, kırılgan bir malzemenin de mimaride kullanılabilirliğini gözler önüne sunmaktadır. Küreselleşme ile birlikte artık dünyada cam her alanda hızlı bir kullanım oluşturmaktadır. İklim şartlarına uygun şekillerde teknoloji ile birlikte mimarla binanın içine ne kadar ışık alınacağı ve ne kadar ısı-soğuk olacağını kontrol edebilmektedir. Mimarlar camın performansını, yüzeye uygulanan cam kaplamalar, cam filmler, farklı cam panellerin sayısı ve camın diğer özelliklerini değiştirerek elde edebilmektedirler.

Makalede buna örnek binalardan ilki Hearst Tower'dir. Bina doğal ışıkla aydınlatılmasını sağlayan cam giydirme cephe, çelik kolanlar ile birlikte kullanılmış kule dışında estetik bir görünüm katarken diğer taraftan da doğal ışıktan faydalanılması sağlanmıştır.

ikinci bina olarak Dans Eden Evlere bakıldığında ise eski ile yeninin bir dönüşümü cam ile sağlanmış, yapıya artı bir farklı estetik görünüm kazandırılmıştır. Diğer bir yapı Aldar gökdelenidir. Gökdelen bulunduğu yörenin özellikleri ile içinden inci çıkan istiridye kabuğundan esinlenerek tasarlanmış ve kullanılan cam kaplama ile alüminyum malzemeler birleştirilerek bir istiridye görüntüsü vermiş; bu da büyük gökdeleni çöl ortasında kocaman bir mercek gibi göstermiştir. Makaledeki diğer iki bina Cartier ve Pompidou Kültür Merkezin de kullanılan cam kaplamalı şeffaf cepheler ise binaların dış tarafındaki ağaç yansımaları ile ayrı bir görünüm ve hassaslık oluşturmuştur. Bu şekilleri ile iki binada bulundukları ortamdan parlak ve cam kaplama cepheler ile çok net ayırt edilir halede görünmektedir.

Yapıldığı dönem itibari ile İngiltere ve Avrupa Birliği'nin en yükse binası olan The Shard ise cam cephesi sayesinde hantal bir kule olmaktan çıkıp cam kaplamaları sayesinde çok zarif bir görüntü oluşturmaktadır. Aynı zamanda kullanılan camlar geometrik döşenmesi ile ve açılır kapanır camlarının açıları sayesinde bina gökyüzünün renlerini de alarak büyüleyici bir görünüm oluşturmaktadır. Başka bir cam kaplamalı yapı ise Cybertecture Egg; dünya 
gezegenini mega yapı olarak taklit eden bir cam kaplama cepheli akıllı yumurta şeklindeki devasa yapıdır. Bu yumurta şeklinde bina cepheye entegre edilmiş güneş fotovoltaik hücrelere sahiptir, böylece güneş enerjisi alternatif elektrik beslemesi sağlamakta ve camlı güneş cephesi, çeşitli tonları ve camı harmanlayan son en son teknoloji olarak kullanılarak muhteşem görünümüm yanında bina içerisinde doğal bir eko sistem oluşturmaktadır. En son yapımı yapı ise Gherkin olarak daha iyi bilinen 30 St Mary Axedir. Binanın tasarımı sayesinde rüzgarı yere yönlendirmek yerine tüm binanın etrafında dolaştırılması sağlanmış ve diagrid bir yapı oluşturmuştur. Bina cephesinde kullanılan cam kaplamalar bu diagrid yapıyı daha görkemli hale getirmiş ve rüzgârın, ışığın bina içinde ve etrafında verimli bir şekilde kullanılmasını sağlamıştır.

\section{KAYNAKÇA}

Ayçam, İ. (2002). "Ekolojik, Akılı Malzemeler", İstanbul, Bilim ve Teknik, Mimarlık Eki, Ed: Gönül Utkutuğ, Tübitak Yayınları.

Altun, D. A. (2009). Sürdürülebilir, Enerji Korunumlu Bir Mimarl>kta "TASARIM", Ege Mimarlık, 28-33.

Cambaz, C. (2009). Tarihi Kentsel Mekanlarda Yer Duygusu ve Yeni Yapı Tasarımı İlişkisi Üzerine Bir İnceleme. Yıldız Teknik Üniversitesi, Fen Bilimleri Enstitüsü Yayımlanmış Yüksek Lisans Tezi, İstanbul.

Masera, G. (2012). The Shard at London Bridge, UK ó Renzo Piano Bulding Workshop, 46-58.

Dilekçi, D. (2000). Elektronik Paradigmaya Geçiş ve İmmateryalite, İstanbul, Domus, sayı: 4, 74-77.

Duralı, İ. K. (2007). Tarihi Çevrede Yeni Yapılaşma Uygulamalarının İrdelenmesi. Mimar Sinan Güzel Sanatlar Üniversitesi, Fen Bilimleri Enstitüsü Yayımlanmış Yüksek Lisans Tezi, İstanbul.

Düzgün, H. (2010). Tarihi Çevrelerde Yeni Yapı Tasarımında Kabuk - Bağlam İlişkisinin Temel ve Güncel Tasarım Kavramları Açısından İncelenmesi. Yıldız Teknik Üniversitesi, Fen Bilimleri Enstitüsü Yayımlanmış Yüksek Lisans Tezi, İstanbul.

Firley.E ve Gimbal, J. (2011). The Urban Towers Hand Book Chichester: John Wiley and Sons.

Futcher, T. (2013). Are Tall Buildings in London Contributing to a Sustainable Urban Future?. University of Kent, United Kingdom.

Hasol, D. (1998). Prag ve Dans Eden Bina, Yapı Dergisi, sayı: 203, 67-78.

Kayhan, P. (2015). Simge Yapıların Tasarımcı - Kullanıcı Bağlamında İmgesel Analizi, İstanbul Teknik Üniversitesi, Fen Bilimleri Enstitüsü Yayınlanmış Yüksek Lisans Tezi, İstanbul.

Munro, D. (2004). Swiss Re's Building, London, STÅLBYGGNADSPROJEKT 36, 36-43.

Okbaz, F. T. Ve Savaşir, K. (2013). Yüksek Yapılarda Çelik Karkas Taşıyıcı Sistem Yerine Çelik Diagrid Kullanımının Avantajları, 5. Çelik Yapılar Sempozyumu, 1-5.

Olcay, E. (2009). Mimari Tasarımda Mimar-Mühendis İlişkisi”, Mimar.İst Dergisi, Sayı: 31, 59-64.

Parker, J. (2012). Bulding The Shard, Ingenia Online, sayı: 52, 25-30.

Piano, R. (2013). The Shard: London Bridge Tower, Matador, 74.

Tohumcu, T. ve Çakmaklı, A. B. (2017). The Integration of Tall Buildings in Urban Environment: Considering The Key Sustainability Concepts, METU JFA 2017/1, 163-186.

Utkutuğ G. (2002). Bilim ve Teknik, Mimarlık Eki, İstanbul, Ed: Gönül Utkutuğ, TübitakYayınları.

Zinzade, D. (2010). Yüksek Yapı Tasarımında Sürdürülebilirlik Boyutunun İrdelenmesi. İstanbul Teknik Üniversitesi, Fen Bilimleri Enstitüsü Yayımlanmış Yüksek Lisans Tezi, İstanbul.

URL-1, (2019). http://www.futureyoungleaders.org/articles/january-2014/cybertectureinnovating-the-fabric-of-mankind/, (Erişim Tarihi: 15.03.2019). 
URL-2, (2019).https://www.kilsanblog.com/mimarlik-farkli-ilginc-yapilar/le-architecture/, (Erişim Tarihi: 15.03.2019).

URL-3, (2019). https://www.fosterandpartners.com/projects/reichstag-new-germanparliament/, (Erişim Tarihi: 21.03.2019).

URL-4, (2019). http://www.fosterandpartners.com/projects/30-stmary-axe/,

(Erişim Tarihi: 15.03.2019).

URL-5, (2019).https://www.insaatburada.com.tr/londranin-ilk-ekolojik-yuksek-binasi/, (Erişim Tarihi: 22.03.2019).

URL-6, (2019). https://www.kilsanblog.com/mimarlik-farkli-ilginc-yapilar/ulusal-gosterisanatlari-merkezi-ncpa/, (Erişim Tarihi: 15.03.2019).

URL-7, (2019). http://www.mimdap.org/?p=1200, (Erişim Tarihi: 11.04.2019).

URL-8, (2019). https://www.kilsanblog.com/mimarlik-farkli-ilginc-yapilar/kunsthaus-graz/, (Erişim Tarihi: 15.03.2019).

URL-9, (2019). https://www.arkitektuel.com/kunsthaus-graz/,

(Erişim Tarihi: 16.03.2019).

URL-10, (2019). http://bestdergisi.com.tr/arsiv-eski/67-yumurta-bina/,

(Erişim Tarihi 16.03.2019).

URL-11, (2019). $\quad$ https://www.archdaily.com/70142/strata-se1-bfls,

(Erişim Tarihi 12.04.2019).

URL-12, (2019). https://www.building.co.uk/30-st-mary-axe-a-gherkin-to-suit-alltastes/3111783.article\#, (Erişim Tarihi 13.04.2019).

URL-13, (2019). http://www.greendesignetc.net, (Erişim Tarihi 13.04.2019).

URL-14, (2019). https://www.arkitektuel.com/dans-eden-ev/,

(Erişim Tarihi 09.04.2019).

URL-15, (2019). http://www.mimdap.org/?p=267, (Erişim Tarihi 30.03.2019).

URL-16, (2019). https://www.fondationcartier.com/en/, (Erişim Tarihi 10.04.2019).

URL-17, (2019). http://www.pariste.net/centre-pompidou/, (Erişim Tarihi 25.03.2019).

URL-18, (2019). https://travel.sygic.com/tr/poi/the-view-from-the-shard-poi:62540， (Erişim

Tarihi 30.03.2019).

URL-19, (2019). https://competition.adesignaward.com/design.php?ID=27372, (Erişim Tarihi 15.03.2019).

URL-20, (2019). http://www.infometcephe.com/cybertecture-egg-akilli-yumurta/, (Erişim Tarihi: 15.03.2019).

URL-21， (2019). http://arquitectura.estudioquagliata.com/tag/the-gherkin, (Erişim Tarihi: 15.03.2019).

URL-22, (2019). https://www.archdaily.com/445413/the-gherkin-how-london-s-famoustower-leveraged-risk-and-became-an-icon/, (Erişim Tarihi: 15.03.2019).

URL-23, (2019). https://www.archdaily.com/64028/ad-classics-centre-georges-pompidourenzo-piano-richard-rogers, (Erişim Tarihi 25.03.2019).

\section{EXTENDED ABSTRACT}

Glass, which is one of the new materials produced during the reflection of technology to design, has been used as an interesting material with a different aesthetic comfort reflecting in the exterior and interior designs of the building and has found the opportunity to be used frequently in architecture in this way. As the developments in glass technology are transferred to architectural design and applications in architecture, it has been seen that the use of glass not only as a lighting tool in architecture but also in cooling and air-conditioning areas has positive effects on energy savings in the architectural field. Glass, which was once only a fragile material, has become a material that can take on many tasks in architecture with the developments in glass technology, so that glass has taken its place in architectural 
field as well as in many other fields. Now it is time to talk about a material that adds aesthetics and appearance to the buildings. World-renowned architects have begun to give a great place to glass in their designs and have made the most striking and remarkable examples of these glass structures. In this study, 9 of these buildings are discussed and their architectural structure and designs are explained.

The first is the Hearst Tower in New York, built by Normen Foster. The building was built in 2006 and has a diamond-shaped appearance. This image of the building is given by exterior glass coating. Another building is the Dancing House (Ginger and Fred) in Prague. The building is formed by the fact that two opposing materials come together side by side and is designed as two dancing pairs. The Dancing House is one side reinforced concrete and the other side is completely glass.

Aldar HQ, known as the Great Sea Shell, is the first round building in the Middle East and the world's first global building. The building has the appearance of a large glass lens in the middle of the desert climate of Abu Dhabi. Immediately after Aldar HQ is the Cartier Center for Contemporary Arts. The building has been placed in a historical environment and a glass structure has been formed, combining old and new buildings.

Immediately behind it is the Kusthaus Art Center in Graz, Australia. The exterior of the building is designed as the most striking part. Acrylic-glass and plastic materials are used in the exterior.

Our 6th Building, one of the most unusual buildings in Paris, is the Pompidou Cultural Center. Pompidou Cultural Center is a transparent building because of the glass and steel façade outside the reinforced concrete structure of the city where it is located, and it is a building that attracts attention because of the colors blue, red, green, yellow.

Another building that is described immediately behind it is Shard, which is known as the fifth highest building in Europe and the 96th highest in the world. The Shard building is a pointed pramide structure with a glass-coated exterior, and the windows are positioned at eight different angles on the façade, creating different perspectives when viewed from the building.

James Law is a glamorous Cybertecture Egg in India. The building is in the center of Bombayi city, with a column-free exterior glass-like world shape. The last building is the 30 St Mary Ax, better known as Gherkin. In London, Gherkin is 180 meters high and consists of 40 floors and has a diagrid shape with glass and steel exterior coatings. 